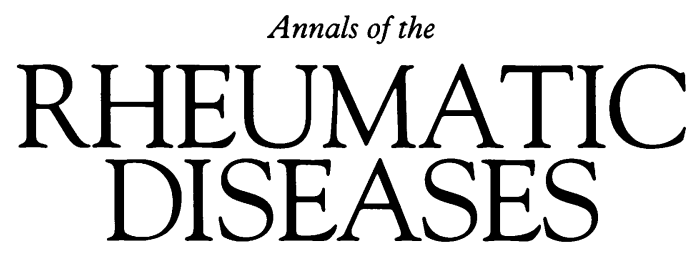

Leader

\title{
Fibromyalgia in the workplace: a 'management' problem
}

When dealing with syndromes of disordered anatomy, such as rheumatoid arthritis and ulcerative colitis, many clinicians will feel a degree of confidence based on familiarity with published data and an expertise based on past personal experience. Such syndromes conform to a traditional medical model of disease, with its emphasis on the rational evaluation of presenting symptoms and signs, leading to probable diagnosis, confirmatory investigations, and scientifically proved treatment regimens. Many of us are less comfortable when confronted by syndromes of disordered function but normal anatomy, such as the irritable bowel, chronic fatigue, and fibromyalgia syndromes. These are often easier to recognise in the clinic than to name or define accurately in the journals, and in the absence of radiographic or serological abnormalities there may be scepticism about their diagnostic validity. British rheumatologists have been slow to recognise the concept of fibromyalgia, whereas our colleagues in Australasia, Scandinavia, and North America feel more comfortable with the diagnosis. Indeed the American College of Rheumatology has officially sanctioned the name, the syndrome, and a set of classification criteria. ${ }^{1}$ These criteria are strict and may be too rigid for routine clinical use.

The typical patient is a young or middle aged woman with a long history of widespread arthralgia and myalgia, prolonged morning stiffness, easy fatigue and poor exercise tolerance, and chronic sleep disturbance. ${ }^{2} \mathrm{~A}$ host of other non-specific features may be present, including headaches, irritable bowel, pelvic pain, non-dermatomal paraesthesia, subjective swelling of the hands, acrocyanosis, mood disturbance, and considerable impairment of function. Signs are few, but include dermatographia and (by definition) multiple tender points at predictable locations. Many patients will have previously consulted a wide range of medical, paramedical, and complementary practitioners, unsuccessfully doctor-shopping with the collusion of their frustrated primary care physician. They may tend to exaggerate their symptoms in an attempt to be taken seriously, but this usually achieves the exact opposite. They are given numerous different diagnoses, subjected to multiple negative investigations, and prescribed ineffective drug and non-drug treatments. Small wonder they become as frustrated as their doctors.

There is no single identifiable cause, but management can focus on potentially important perpetuating factors, such as poor sleep, lack of physical fitness, and bad posture. A reasonable approach involves firm reassurance that no sinister disease is present, an explanation about the complex nature of chronic pain, advice on weight loss, stretching of soft tissues, aerobic fitness, and how to cope with stress. In addition low dose tricyclic drugs taken midevening may improve sleep. Active patient participation in management should be encouraged. Many derive benefit from aqua-aerobics, aromatherapy, and massage. An optimistic attitude is essential: 'Mens sana in corpore sano'.

In some cases the patient relates the onset of symptoms to a specific event. Not infrequently there has been a previous industrial or road traffic accident (with 'whiplash' injury), often complicated by unresolved litigation. An increasing number attribute their illness to faulty workplace ergonomics or activities, often involving sustained poor posture of the neck or low back, or repetitive movements of the hands and wrists. Many are referred with possible 'repetitive strain injury' ('RSI'), either by their general practitioner or their solicitor. Is this syndrome the modern equivalent of 'telegraphists' cramp' and other 'occupational/craft neuroses'? The traditional medical model proposes that mechanical soft tissue strains, with or without actual evidence of injury, will resolve in a matter of weeks or months, especially if the putative posture or activity is avoided. What, then, is the catalyst which converts a local/acute pain problem into a generalised/chronic pain syndrome? How and why does local pain metastasise, initially throughout the limb, and then sometimes the rest of the body?

Regional forms of fibromyalgia are common. An acute cervical strain can evolve to pain throughout an arm, associated with hyperaesthesia, paraesthesia, and multiple tender points. The pain may eventually become bilateral, or develop into a reflex sympathetic dystrophy. ${ }^{3}$ Similarly, acute mechanical low back strain can become associated with diffuse pain in the lower limb, plus tenderness over the posterior pelvic brim, glutei, trochanter, and collateral ligaments of the knee on the side ipsilateral to the initial back pain. Such 'pain amplification' is likely to have a multifactorial pathogenesis. Smythe explained it in terms of referred pain from deep somatic structures, through mechanical stresses on ligaments in the cervical and lumbar spines. ${ }^{4} \mathrm{He}$ proposed that 'RSI' is referred pain from the neck. Perhaps prolonged periods of neck flexion, and static contraction of proximal limb and truncal antigravity muscles, are the cause of distal limb discomfort. A psychological basis has been proposed under the general term 'attitudinal pathosis'. ${ }^{5}$ It may be explained purely in terms of disordered neurochemistry. Fibromyalgia, both 
regional and general, may be marked by prominent dermatographia. ${ }^{6}$ This appears to be due to increased neurogenic inflammation, mediated by the release of substance $P$ and calcitonin gene-related peptide through axon reflexes. These peptides also mediate nociception through C-polymodal nociceptors at their synapses in the dorsal horn. There may be heightened sympathetic activity, lowering the threshold for nociceptor activation. ${ }^{7}$ There may also be dysregulation of neurohormones in the brain, dorsal horn, and pathways in between. ${ }^{8}$

The Australian experience of the 1970s and 1980s suggests that occupational pain amplification may also have a 'psychosocioeconomic' basis. The workers' compensation and health care delivery systems were almost bankrupted by a socially divisive and fiscally ruinous epidemic of regional pain in the arms of keyboard operators and process workers. ${ }^{3}$ A number of inexplicable anomalies were highlighted, however, by epidemiological studies of occupational pain in the arm. It was rare in self employed subjects, and more common in those with mundane, repetitive jobs, and with little job satisfaction. On the other hand, it was common in musicians who spend many hours practising, and who may well be under considerable stress, but whose job satisfaction is assumed to be high. It could spread rapidly throughout one part of a company but hardly affect similar offices in the same company, even within the same building. Companies with branches in Australia and Europe noted the problem only in their Australian employees, despite the fact that all workers were using equivalent hardware. Women were more commonly affected than men. The incidence was higher just before school holidays, and, in seasonal workers (such as fruit pickers), just before the end of the season. 'Repetitive strain injury' was also more common in companies whose volume of work was decreasing, and in public sector employees.

After much rancorous debate in the medical and lay press, and protracted medicolegal wrangling, a fragile consensus was reached that the epidemic might be related to the inappropriate interaction of the patient with traditional-model medicine; an adversarial legal system; powerful and militant trades unions; ill-informed and unsympathetic employers; a generous compensation system for occupational pain problems; sensationalist media attention and scaremongering; misguided but vocal self help groups; faulty belief about the relation between pain and injury; and socioeconomic pressures in a country heading towards recession. ${ }^{3} 910$

The Australian epidemic of occupational fibromyalgia began to subside for a variety of reasons. ${ }^{11}{ }^{12}$ Society at large became less sympathetic towards those with 'RSI'. Large sums were being awarded in compensation in the absence of any objective evidence of injury, and sufferers were accused of being 'bludgers', milking the State of finite resources. Doctors and other health professionals became more objective, and stopped overinvestigating and overtreating sufferers. The courts began to find against litigants persuing claims at common law. Media interest waned. And, of course, there were many necessary improvements in workplace ergonomics. An interesting parallel can be drawn from 'whiplash' injury in the state of Victoria. The number of financial claims rose steadily in the early to mid-1980s despite improvements in car safety. Then in 1986 new legislation was introduced to try to reduce the number of dubious claims. The number fell dramatically. The apparent epidemiology of a soft tissue pain problem had been influenced by a change in the láw. ${ }^{13}$

What lessons has Britain learnt from the Australian experience? Very few, unfortunately. Much of the medical debate was published in the Medical fournal of Australia and went unread by British rheumatologists. General practitioners and consultants still use the facile acronym 'RSI' to explain the unproved concept of pain being due to an injury caused by the strain of repetitive movements. (RSI has also been used to denote 'rampant social iatrogenesis'.) The media give uncritical attention to 'worst-case-scenario' sufferers. The Health and Safety Executive prepares reports on the 'three stages of RSI', causing alarm among workers and raising their expectation that today's minor pain is tomorrow's chronic disability. Doctors continue to prescribe splints, drugs, long periods off work, and courses of physiotherapy, and justify this with the diagnosis 'tenosynovitis', or similar. Unions push members to litigate against what they see as unscrupulous bosses, whose lack of tact and sympathy may alienate the worker. Self help groups have been formed to educate sufferers about their condition and how to claim compensation. Office workers can now consult a 'survival handbook', a publication with a distinctly feminist slant. ${ }^{14}$ A book has been published entitled Repetitive Strain Injury: The Keyboard Disease ${ }^{15}$ and conferences have been held on the same topic. And the Department of Social Security makes 'Cramp of the hand or forearm due to repetitive movements' a 'disease', prescribed under the Industrial Injuries Provisions of the Social Security Act $1975 .{ }^{16}$ This listing (PD A4) is a triumph of bureaucracy over logic. It states that 'The condition is probably due to a combination of physical fatigue of muscles and an underlying psychoneurosis'. There is no solid evidence of either. Although occurring in occupations '... involving prolonged periods of handwriting or typing', it then states that it is 'now usually diagnosed in professional musicians'. It suggests that there may be 'spasm, tremor, and pain', and yet then says there are no physical signs! Despite being a prescribable disease, the harmful effects are apparently 'not precisely known'. Lastly, it indicates that 'the disease should be presumed to be due to the nature of the occupation unless there is evidence to the contrary'. By that criterion tennis elbow should be due to being a professional tennis player. When, to all of the above factors, is added economic recession in Britain, then all the pieces are in place for an epidemic of regional fibrositic pain in the arms, and possible subsequent generalised fibromyalgia syndrome.

How are we to tackle this potential epidemic? If the diagnosis is unclear, the family doctor should avoid using a specific diagnosis, such as tenosynovitis or 'RSI' on the initial sickness certificate. If a full history and examination, conducted in a non-judgmental fashion, shows no evidence of an obvious organic rheumatological or orthopaedic condition the hospital specialist should consider a descriptive diagnosis such as 'upper limb regional chronic pain syndrome', and avoid unnecessary investigation. This may merely serve to convince the patient that a serious illness remains undiscovered. Unproved remedies should be avoided, especially prolonged courses of physiotherapy which are requested as a convenient way of getting the patient out of one's hair for a few months. The problem is unlikely to resolve unless any underlying ergonomic, psychological, or interpersonal issues are explored. Splints, collars, and slings should not be prescribed: these are part of an instantly recognisable uniform of disability and disease, and may serve to reinforce illness behaviour. No body tissue benefits from prolonged periods of disuse: muscles atrophy, ligaments tighten, and bone may become porotic. A reduction of inappropriate activity or temporary change of activity is more physiological. Office and assembly line designs should take account of ergonomic factors: most competent occupational therapists can 
identify potential design faults, if asked. Work stations should be adaptable to the differing height and build of the various employees who will be called upon to use them. Management should learn to care for the employees as individuals, and show genuine concern for their physical and emotional wellbeing in the workplace. Process and keyboard workers should be allowed a few minutes every hour to stretch muscles made tense by the postural requirements of the task, and given an educational sheet about which exercises are best. Trade union pressure has already made breaks mandatory for VDU operators, and limited the total time spent using a VDU in any shift. Keyboard stroke rates have to be realistic, and the worker should be able to control the machine, rather than vice versa. Every attempt should be made to rehabilitate those with pain at their place of work, rather than away from it on sick leave. Employees should consider their long term place in the workforce, rather than any short term financial gain from successful litigation: people who sue for pain problems attributed to their work may render themselves permanently blacklisted by potential future employers.

The problem of fibromyalgia in the workplace is complex and multifactorial. Many of the observations on pain in arms apply equally to the management of occupational low back pain. ${ }^{17}$ Both require serious study if doctors are to avoid colluding unwittingly in the perpetuation of an Australian-type epidemic, with its unfortunate effects on individuals in particular and society in general.
Frimley Park NHS Trust Hospital,

Portsmouth Road,

Frimley, Camberley,

Surrey GU16 5UF,

United Kingdom

1 Wolfe F, Smythe H, Yunus M B, et al. The American College of Rheumatology 1990 criteria for the classification of fibromyalgia. Report of the multicentre criteria committee. Arthritis Rheum 1990; 33: 160-72.

2 Wolfe F. Fibromyalgia: the clinical syndrome. Rheum Dis Clin North Am 1989; 15: 1-18.

3 Littlejohn G O. Fibrositis/fibromyalgia in the workplace. Rheum Dis Clin North Am 1989; 15: 45-60.

4 Smythe $H$. The "repetitive strain injury syndrome" is referred pain from the neck. F Rheumatol 1988; 15: 1604-8.

5 Kamman G R. Traumatic neurosis, compensation neurosis, or attitudinal pathosis. AMA Archives of Neurology and Psychiatry 1951; 65: 593-603.

6 Littlejohn G O, Weinstein C, Helme R D. Increased neurogenic inflammation in fibrositis syndrome. $\mathcal{F}$ Rheumatol 1987; 14: 1022-5.

7 Vaeroy H, Qiao Z G, Morkrid L, Forre O. Altered sympathetic nervous system response in patients with fibromyalgia (fibrositis syndrome). $\mathcal{f}$ Rheumatol 1989; 16: 1460-5.

8 Russell I J. Neurohormonal aspects of fibromyalgia syndrome. Rheum Dis Clin North Am 1989; 15: 149-68.

9 Cleland L. "RSI": a model of social iatrogenesis. Med f Aust 1987; 147: 236-9.

10 Bell D S. "Repetition strain injury": an iatrogenic epidemic of simulated injury. Med $\mathcal{f}$ Aust 1989; 151: 280-4.

11 Wright G D. The failure of the "RSI" concept. Med f Aust 1987; 147: 233-6.

12 Ferguson D A. "RSI": putting the epidemic to rest. Med f Aust 1987; 147: 213-4.

13 Reilly P A, Travers R, Littlejohn G O. Epidemiology of soft-tissue rheumatism: the influence of the law. $\mathcal{F}$ Rheumatol 1991; 18: 1448-9.

14 Craig M, Phillips E. Office workers' survival handbook. Fighting health hazards in the office. London: The Women's Press, 1991.

15 Huskisson E. Repetitive strain injury. The keyboard disease. London: Charterhouse Conference and Communications, 1992.

16 Department of Social Security. Notes on the diagnosis of prescribed diseases. London: HMSO, 1991.

17 Brooks P M. Back pain in the workplace. Med f Aust 1987; 147: 267-8. 